\title{
Os principais documentos internacionais da educação ambiental apresentados em um mini-curso de formação inicial de professores a partir do fazer artístico
}

The main international documents of environmental education presented in a minicourse of initial training of teachers from the artistic facts

Los principales documentos internacionales de la educación ambiental presentados en un mini-curso de formación inicial de profesores a partir del hacer artístico

Antonio Fernandes Nascimento Junior Professor Doutor, UFLA, Brasil. toni_nascimento@yahoo.com

Daniele Cristina de Souza Professora Doutora, UFTM, Brasil. danicatbio@yahoo.com.br

\section{Rosangela Alves Tristão Borem} Professora Doutora, UFLA, Brasil. tristaoborem@gmail.com

Camila Oliveira Lourenço Mestranda, UFLA, Brasil. camila_olourenco@hotmail.com 


\section{RESUMO}

A questão central deste trabalho foi o relato e discussão de práticas pedagógicas alternativas na forma de expressões artísticas desenvolvidas em um minicurso baseado na pedagogia de projetos. Foram trabalhadas a Carta de Belgrado (1975), o Tratado de Tbilisi (1977), o Tratado de Educação Ambiental para Sociedades Sustentáveis e Responsabilidade Global - ECO 92 (1992), a Declaração de Thessaloniki (1997), A Carta da Terra (2000) e o Documento da Rio + 20 - o rascunho zero e a carta final "O Futuro Que Queremos" (2012). As práticas alternativas foram: teatro de fantoches; história em quadrinhos; imagens selecionadas via internet; teatro convencional; júri simulado; e painéis interpretativos construídos. As atividades foram filmadas e, posteriormente, analisadas e revelaram uma eficiência pedagógica relevante tanto do ponto de vista conceitual como atitudinal e procedimental.

PALAVRAS CHAVES: Educação ambiental. Práticas Pedagógicas Alternativas. Arte e Educação Ambiental.

\section{ABSTRACT}

The central question of this work was the practical story and quarrel of pedagogical alternatives in the form of artistic expressions developed in one mini pedagogy established course of projects. They had been worked the Letter of Belgrade (1975), the Treated one to Tbilisi (1977), Treated to Ambient Education for Sustainable Societies and the Global Responsibility - ECO 92 (1992), the Declaration of Thessaloniki (1997), the Letter of the Land (2000) and Document of the River + 20 - [[o]] rough draft the zero and final letter "the Future That We want" (2012). The practical alternatives had been: theater of puppets; history in quadrinhos; selected images way Internet; conventional theater; simulated jury; e constructed interpretativos panels. activities had been filmed e, later, analyzed and had disclosed an efficiency pedagogical excellent as much of the conceptual point of view as atitudinal e procedural.

WORDS KEYS: Ambient Education. Practical Pedagogical Alternatives. Art and Environment Education.

\section{RESUMEN}

La cuestión central de este trabajo fue el relato y discusión de prácticas pedagógicas alternativas en la forma de expresiones artísticas desarrolladas en un minicurso basado en la pedagogía de proyectos. La Carta de Belgrado (1975), el Tratado de Tiflis (1977), el Tratado de Educación Ambiental para las Sociedades Sostenibles y la Responsabilidad Global - ECO 92 (1992), la Declaración de Thessaloniki (1997), La Carta de la Tierra (2000) y el Documento de Río + 20 - el borrador cero y la carta final "El Futuro Que Queremos" (2012). Las prácticas alternativas fueron: teatro de títeres; historia de cómics; imágenes seleccionadas vía internet; teatro convencional; jurado simulado; y paneles interpretativos construidos. Las actividades fueron filmadas y, posteriormente, analizadas y revelaron una eficiencia pedagógica relevante tanto desde el punto de vista conceptual como a la actitudinal y procedimental.

PALABRAS CLAVES: Educación Ambiental. Prácticas Pedagógicas Alternativas. Arte y Educación Ambiental. 


\section{INTRODUÇÃO}

A utilização de materiais do fazer artístico didático-pedagógicos como motivadores de aprendizagem tem se mostrado importante ferramenta para a educação ambiental, pois proporciona um grande interesse dos alunos por se apresentar de forma participativa, dinâmica e descontraída (GONÇALVES et al., 2012).

Por outro lado, Nascimento Junior e Souza (2009), entendem que a arte utilizada na educação ambiental, pode servir para familiarização inicial com determinado tema; para a superação individual e compartilhamento coletivo; e, ainda, ser um reforço para instigar a busca de mais conhecimentos.

A utilização de recursos didáticos produzido pelos educandos, por sua vez, pode ser uma ferramenta auxiliar importante no trabalho do educador na educação ambiental. Nesta ação conjunta acontecem interações que podem favorecer cooperação, questionamentos, reflexão, avaliação dos conhecimentos e capacidades dos educandos e educadores (NASCIMENTO JUNIOR E SOUZA, 2009).

Diante deste fato, o trabalho com projetos expressa uma proposta de educação capaz de associar o conteúdo à afetividade, cuja preocupação é a formação de competências com participação ativa dos alunos (OLIVEIRA, 2006).

Este trabalho teve como objetivo o relato e discussão de um minicurso voltado para formação inicial de professores, desenvolvido a partir dos documentos internacionais da educação ambiental trabalhados em práticas pedagógicas alternativas na forma de expressões artísticas adaptadas à pedagogia de projetos.

\section{DESENVOLVIMENTO}

\section{Descrição do minicurso:}

O minicurso em questão foi organizado pelo Programa Institucional de Bolsas de Iniciação à Docência - PIBID, da biologia e oferecido aos seus integrantes e à população acadêmica em geral. Tinha como preocupação central a formação inicial de professores. Seu eixo era a educação ambiental desenvolvida a partir de alguns dos principais documentos internacionais orientadores da sua prática. Os documentos foram: a Carta de Belgrado (1975), o Tratado de Tbilisi (1977), o Tratado de Educação Ambiental para Sociedades Sustentáveis e Responsabilidade Global - ECO 92 (1992), a Declaração de Thessaloniki (1997), A Carta da Terra (2000) e o Documento da Rio +20 o rascunho zero e a carta final "O Futuro Que Queremos"(2012).

\section{METODOLOGIA}

O curso foi planejado e executado dentro da metodologia de projetos valorizando, a seu tempo, os conteúdos dos documentos. Esta informação é importante já que, originalmente, a metodologia de projetos valorizava, de forma prioritária, os processos que envolvem o aprendizado em detrimento do conteúdo a ser aprendido.

A metodologia de projetos foi escolhida pois ela trabalha com a afetividade, fortalecendo o componente lúdico e potencializando o ensino e aprendizagem (OLIVEIRA, 2006). Segundo a autora, esta metodologia estimula a capacidade de falar, escutar, escolher e decidir. Propiciam 
aos estudantes um aprendizado com alegria e a necessidade de pesquisar e construir, desenvolvendo habilidades essenciais para sua formação.

Os projetos foram desenvolvidos por grupos de quatro a seis alunos formados pelos participantes do curso que perfaziam um total de vinte e oito alunos licenciandos em Biologia. Foram formados seis grupos.

O desenvolvimento do curso ocorreu em duas partes. A primeira foi teórica trabalhada em um dia (8 horas). Esta apresentação ofereceu o conteúdo para o desenvolvimento dos projetos subsequentes, organizados e desenvolvidos pelos grupos.

$\mathrm{Na}$ segunda etapa, os alunos desenvolveram atividades práticas que consistiam em se reunirem em grupos, escolherem o documento a ser trabalhado e um recurso didático para apresentar o documento escolhido. As atividades práticas duraram três dias (24 horas).

\section{Relato da atividade desenvolvida:}

\section{A parte teórica: Subsídios para a construção de projetos}

O enfoque teórico foi realizado por meio de uma contextualização do tema a partir da cronologia dos principais documentos internacionais da educação ambiental e consistia, de forma resumida, no seguinte relato:

A primeira conferência internacional sobre educação ambiental aconteceu em 1975 em Belgrado em resposta aos problemas ambientais das décadas anteriores. Neste período, a UNESCO promoveu um Encontro Internacional Em Educação Ambiental onde foi criado o Programa Internacional de Educação Ambiental - PIEA que formulou princípios orientadores os quais estão presentes na Carta de Belgrado. Esta afirma a necessidade de uma educação ambiental continuada, multidisciplinar, integrada às diferenças regionais e voltada para os interesses nacionais. Insere as questões sociais e éticas nos discursos ambientais propondo temas para a erradicação da pobreza e da exploração entre os países. Por último, propõe um programa mundial de Educação Ambiental.

Em 1977, acontece a Conferência Intergovernamental de Educação Ambiental em Tbilisi, também organizada pela UNESCO com a colaboração o Programa das Nações Unidas para o Meio Ambiente (PNUMA). Nesta conferência foram definidos os objetivos, as características e as estratégias da educação ambiental no plano nacional e internacional.

A ONU, em sua Resolução no 37/7, de 28.10.1982, redige a Carta Mundial da Natureza. A primeira declaração intergovernamental a se preocupar com o respeito pela natureza como um princípio básico de proteção à mesma.

Em 1987 acontece o Congresso Internacional sobre Educação e Formação Relativas ao Meioambiente, realizado em 1987 em Moscou, Rússia, também promovido pela UNESCO. Neste congresso é escrita a Estratégia Internacional de ação em matéria de educação e formação ambiental para o decênio de 90. Este documento ressalta a importância da formação de recursos humanos nas áreas formais e não formais da Educação Ambiental e na inclusão da dimensão ambiental nos currículos de todos os níveis.

Em 1990 a Conferência Mundial sobre Educação para Todos, realizada em Jontien, Tailândia, de 5 a 9 de março de 1990, aprova a Declaração Mundial sobre Educação para Todos: Satisfação das Necessidades Básicas de Aprendizagem.

Em 1992, ocorre a II Conferência das Nações Unidas sobre Meio Ambiente e Desenvolvimento Humano, RIO-92. Foram produzidos diversos acordos, protocolos, convenções sendo o texto fundamental à educação ambiental o Tratado de Educação Ambiental para Sociedades Sustentáveis e Responsabilidade Global. Seus principais princípios 
consideram que a educação ambiental é um ato político baseado em valores para a transformação social e deve ter como base o pensamento crítico e inovador e ter o propósito de formar cidadãos com consciência local e planetária, que respeitem a autodeterminação dos povos e a soberania das nações valorizando as diferentes formas de conhecimento. Deve, também, ajudar a desenvolver uma consciência ética sobre todas as formas de vida.

Também no Rio de Janeiro, durante a Eco 1992, acontece a Cúpula da Terra a que encaminha a criação de uma Carta da Terra, aceita internacionalmente. Entretanto os governos adotam a Declaração do Rio de Janeiro sobre Meio Ambiente e Desenvolvimento Sustentável em lugar da Carta.

Em 1997 acontece a Conferência Internacional sobre Meio Ambiente e Sociedade: Educação e Consciência Pública para a Sustentabilidade em Thessaloniki; onde se reconhece que o desenvolvimento da educação ambiental, até então, foi insuficiente. Na conferência a educação ambiental, a economia, a tecnologia e a legislação, são vistas como as bases da sustentabilidade

Ainda em 1997, durante o Fórum Rio+5 no Rio de Janeiro, a Comissão da Carta da Terra convoca sua primeira reunião. No entanto, o lançamento público da Carta da Terra acontece em junho de 2000 em Haia. Esta é uma declaração de princípios éticos para a construção de uma sociedade mais justa, sustentável e pacífica, ressaltando a interdependência e a responsabilidade partilhada de todos os povos para com o bem-estar da comunidade de vida global.

Em 2012, a RIO+20 produz um documento - o rascunho zero e a carta final "O Futuro Que Queremos" (2012) que busca inserir a perspectíva da economia verde no contexto do desenvolvimento sustentável, da erradicação da pobreza e apresentar o quadro institucional para o desenvolvimento sustentável.

\section{A parte prática:}

As atividades práticas se iniciaram com a formação de seis grupos, cada um com seu tema, respectivamente nomeados de 1 a 6 . Os grupos tiveram 1 dia para escolher e construir sua ferramenta. As apresentações aconteceram durante dois dias subsequentes. Ao final de cada atividade foi feita uma discussão e avaliação da prática com os participantes. Todas atividades foram filmadas e, posteriormente, analisadas. 


\section{A escolha das ferramentas didáticas pelos grupos:}

As atividades foram realizadas no Museu de História Natural da UFLA e consistiram de dois momentos. No primeiro, cada grupo escolheu seu documento e fez sua leitura crítica. Em seguida cada grupo escolheu uma ferramenta didática para apresentar o documento a todos os outros grupos, sendo estas:

Grupo 1 - A carta de Belgrado (1975) apresentada a partir da construção e apresentação de um teatro de fantoches tendo como objetivo: (1) Construir, de forma coletiva, um teatro de fantoches capaz de sintetizar e expressar a essência da Carta de Belgrado; (2) Apresentar a linguagem lúdica do teatro como fator motivador e simplificador da história, do contexto e dos conceitos da questão da Educação Ambiental (EA) contidos na carta; (3) Utilizar a prática de construção de uma peça teatral como forma de elaboração do conhecimento apresentado em um curso de EA cujo momento se concentrava na Carta de Belgrado.

Grupo 2 - Tratado de Tbilisi (1977) apresentado a partir da elaboração e construção de uma revista em quadrinhos cujo objetivo foi: (1) Construir, de forma coletiva, uma revista em quadrinhos capaz de sintetizar e expressar a essência do Tratado de Tbilisi; (2) Apresentar a linguagem lúdica dos quadrinhos como fator motivador e simplificador da história, do contexto e dos conceitos da questão da EA contidos na carta; (3) Utilizar a prática de construção de uma revista em quadrinhos como forma de elaboração do conhecimento apresentado em um curso de EA cujo momento se concentrava na Carta de Belgrado.

Grupo 3 - Tratado de Educação Ambiental para Sociedades Sustentáveis e Responsabilidade Global - ECO 92 (1992) - apresentado por textos elaborados a partir de imagens selecionadas via internet e apresentadas de forma expositiva. O qual procurou (1) Construir, de forma coletiva, um conjunto de textos capaz de sintetizar e expressar o Tratado de EA para Sociedades Sustentáveis e Responsabilidade Global - elaborado em 1992 durante a II Conferência das Nações Unidas sobre Meio Ambiente e Desenvolvimento Humano, RIO -92; (2) Apresentar a linguagem lúdica da imagem fotográfica como fator motivador e simplificador da história, do contexto e dos conceitos da questão da EA contidos no tratado; (3) Utilizar a prática de construção de uma texto a partir de imagens escolhidas como forma de elaboração do conhecimento apresentado em um curso de EA cujo momento se concentrava no Tratado de EA para Sociedades Sustentáveis e Responsabilidade Global.

Grupo 4 - Declaração de Thessaloniki (1997) apresentada a partir da construção e apresentação de um teatro que buscou (1) Construir, de forma coletiva, um teatro capaz de sintetizar e expressar a essência da Declaração de Thessaloniki; (2) Apresentar a linguagem lúdica do teatro como fator motivador e simplificador da história, do contexto e dos conceitos da questão da EA contidos na carta; (3) Utilizar a prática de construção de uma peça teatral como forma de elaboração do conhecimento apresentado em um curso de EA cujo momento se concentrava na Declaração de Thessaloniki.

Grupo 5 - A Carta da Terra (2000) apresentada a partir da construção e apresentação de um júri simulado o qual se concentrou em (1) Construir, de forma coletiva, um júri simulado capaz de sintetizar e expressar a essência da Carta da Terra (2) Apresentar a linguagem do júri simulado como fator motivador e simplificador da história, do contexto e dos conceitos da questão da EA contidos na carta; (3) Utilizar a prática de construção de um júri simulado como forma de elaboração do conhecimento apresentado em um curso de EA cujo momento se concentrava na Carta da Terra.

Grupo 6 - Documento da Rio + 20 - o rascunho zero e a carta final "O Futuro Que Queremos" (2012) apresentado a partir da imagem de vídeos que pudessem gerar a construção de painéis interpretativos procurando (1) Construir, de forma coletiva, um conjunto de textos capaz de 
sintetizar e expressar o Documento sobre a EA da Rio + 20; (2) Apresentar a linguagem lúdica da imagem fotográfica como fator motivador e simplificador da história, do contexto e dos conceitos da questão da EA contidos no tratado; (3) Utilizar a prática de construção de uma texto a partir de imagens escolhidas como forma de elaboração do conhecimento apresentado em um curso de EA cujo momento se concentrava no Tratado de EA para Sociedades Sustentáveis e Responsabilidade Global.

\section{A construção e apresentação das ferramentas didáticas:}

No segundo momento, foi realizada pelos grupos a adaptação dos documentos para as ferramentas escolhidas. O processo consistiu na elaboração de um texto cuja linguagem utilizada foi aquela estabelecida pela ferramenta em questão: linguagem do teatro (convencional, de fantoches e júri simulado), dos quadrinhos e dos painéis de imagens.

Para o teatro de fantoches sobre a carta de Belgrado, desenvolvido pelo grupo 1, foi necessária a construção dos fantoches e do cenário, os quais foram confeccionados a partir de imagens pesquisadas na internet. 0 site utilizado foi (http://www.painelcriativo.com.br/2008/06/01/como-fazer-fantoche-de-feltro-oueva/). material utilizado para sua confecção foi tecido das cores amarela, marrom, azul, verde, preta e branca, cola quente, grampeador, papel Collor set, material reciclável, canetinha hidrocor, espuma, tesoura e papel crepom. O cenário foi construído com E.V.A (Etil Vinil Acetatol), papel cartão, papel crepom, papel de seda, cola-quente e tecidos.

A peça foi desenvolvida a partir das falas de seis animais da região (papagaio, onça, sagui, tucano, coruja e tamanduá bandeira). Foi ensaiada e apresentada. A apresentação foi precedida da exibição de um curta metragem "Rosa de Hiroshima" de 4min13seg-autor Mabarrosf, postado em17/04/2011, a fim de contextualizar os acontecimentos anteriores a Carta de Belgrado. Em seguida iniciou-se a apresentação do teatro.

Para a história em quadrinhos sobre o Tratado de Tbilisi, desenvolvida pelo grupo 2, foi utilizado o site (http://www.makebeliefscomix.com), gratuito e disponível na internet. Posteriormente, o grupo começou a pensar na história para abordar o Tratado de Tbilisi e optaram por criar quatro personagens que estariam dialogando como se estivessem na Conferência. $O$ texto então foi criado, tendo a preocupação da linguagem acessível a todo tipo de público (NASCIMENTO JÚNIOR e SOUZA, 2009) e com isso iniciou-se a confecção dos quadrinhos. Após a confecção da HQ optou-se por apresentá-la em mídia Power Point e os integrantes faziam as falas simultaneamente à exibição.

As imagens selecionadas via internet e apresentadas sobre o Tratado de Educação Ambiental para Sociedades Sustentáveis e Responsabilidade Global - ECO 92, trabalhados pelo grupo 3, foram interpretadas e produziram-se textos a partir desta interpretação.

O teatro sobre a Declaração de Thessaloniki, elaborado e apresentado pelo grupo 4, foi realizado em forma de uma conferência. Foram criados oito personagens (o coordenador, uma catadora de materiais recicláveis, duas professoras, uma cientista, um representante da mídia, um representante do governo e manifestante de ONGs). Estes personagens eram os atores sociais que constituíam a própria Conferência de Thessaloniki e conversavam entre si o próprio conteúdo da conferência. A partir disso o grupo confeccionou o cenário, figurino e acessórios a serem usados na apresentação. Foram realizados os ensaios da peça e, em seguida, iniciou-se a apresentação do teatro. 
O júri simulado sobre a Carta da Terra, escrito e apresentado pelo grupo 5 foi elaborado na forma de um julgamento cujos personagens participantes eram os atores sociais que expressavam no conteúdo da Carta. Tais personagens foram: a juíza, o promotor, três acusadas: a presidenta do Brasil (ausente), uma empresária e uma trabalhadora. Os jurados eram o público em geral.

A construção de painéis interpretativos sobre o Documento da Rio +20 - o rascunho zero e a carta final "O Futuro Que Queremos" (2012), desenvolvida pelo grupo 6, foi feito a partir da orientação de se confeccionarem cartazes com desenhos referentes as principais propostas do documento apresentadas em power point. Estes cartazes foram, posteriormente, apresentados e discutidos com os integrantes de todos os grupos. Sendo assim, grupos de quatro alunos foram formados e disponibilizados cartazes e materiais sendo estes: caneta estereográfica, giz de cera, lápis de cor, papel crepom. Foi estabelecido que seriam utilizados 30 minutos para a confecção dos cartazes. Após o termino do trabalho este foi avaliado pelos participantes.

\section{RESULTADOS E DISCUSSÃO}

\section{As impressões dos participantes:}

Em todas as atividades a análise da fala, transcrita a partir das gravações, identificou pontos que fortaleciam a prática desenvolvida. O Aluno 1, falando sobre o teatro que encenou a Declaração de Thessaloniki ", relatou (...) vocês conseguiram passar bem os conceitos da carta e foi engraçado". O mesmo aconteceu acerca do júri simulado sobre a Carta da Terra, onde um participante falou "Esta atividade possibilitou a construção de aspectos importantes sobre a carta da Terra de maneira interativa e motivadora, tornando mais fácil a compreensão destes princípios. Adorei a atividade". Outro participante afirmou que "Este tipo de atividade proporcionou uma maior interação não só entre os participantes do júri simulado como também entre os participantes e a plateia. Foi legal, foi totalmente diferente".

Outro ponto positivo foi a confiança adquirida pelos alunos, vista na seguinte fala: "Nunca pensei que fosse capaz de construir um júri simulado em tão pouco tempo, superei minhas próprias expectativas".

\section{Um pouco de discussão:}

Em conformidade com as ideias de Oliveira (2006), expressas na introdução deste artigo, os resultados das atividades indicaram que o resgate do componente lúdico contido na metodologia de ensino por projetos, potencializou o processo de ensino e a aprendizagem. As técnicas do fazer artístico, desenvolvidas para fins didático-pedagógicos no trabalho, se apresentaram como motivadores de aprendizagem conforme afirmam Ferreira et al. (2012) e Gonçalves et al. (2012).

A respeito do teatro de fantoches sobre a carta de Belgrado, os resultados alcançados resultam semelhantes aqueles encontrados em Santos et al. (2006), Gonçalves et al. (2012) e Ferreira et al. (2012) para quem a experiência com teatro de fantoches proporcionou uma construção bastante significativa de conhecimentos conceituais. Estes autores ressaltaram nesta prática de ensino aspectos positivos ligados a motivação e criatividade. E, concluíram que esta se apresentava como uma interessante prática de ensino na formação inicial e continuada de professores. 
Situação semelhante é encontrada na atividade ligada à elaboração de histórias em quadrinhos sobre o Tratado de Tbilisi. Os resultados deste trabalho estão em sintonia com aqueles obtidos por Galante et al. (2006), Macagnan et al. (2006) e Rauber e Nascimento Junior (2007), Lisboa et al. (2008) e Caruso e Silveira (2009). Estes autores concluíram que as histórias em quadrinhos se mostram como um importante veículo para a informação, produção de significados e sensibilização das crianças, jovens e adultos. Valorizam, também, a imaginação como elemento fundamental da presença do fazer artístico na educação ambiental e no ensino de ciências.

Quanto ao trabalho desenvolvido a partir das imagens selecionadas via internet e apresentadas sobre o Tratado de Educação Ambiental para Sociedades Sustentáveis e Responsabilidade Global - ECO 92, este, também se aproximou dos relatos apresentados por Nascimento Junior et al. (2001), Colognese e Nascimento Junior (2004), Ghellere et al. (2006) e Souza et al. (2008). Estes trabalhos sustentam a eficiência das práticas desenvolvidas com painéis de imagens.

Falando do teatro sobre a Declaração de Thessaloniki, seus resultados se aproximaram das experiências de sucesso pedagógico relatadas por Montenegro et al. (2005), Formighieri et al. (2006), Macagnan e Nascimento Junior (2006), Mello e Cortelazzo (2006), e Silveira et al. (2009).

Já, o júri simulado sobre a Carta da Terra apresentou resultados expressando uma importância pedagógica relevante tanto nos aspectos conceituais como atitudinais da prática, fortalecendo, inclusive, a argumentação dos participantes. Tais resultados são encontrados, de forma semelhante, nos trabalhos de Real e Menezes (2008), Ferry e Nagem (2009) e Oliveira (2011)

Por último, a construção de painéis interpretativos sobre o Documento da Rio $+20-0$ rascunho zero e a carta final "O Futuro Que Queremos" (2012) feito a partir de desenhos dos participantes também encontrou relevância pedagógica à semelhança de alguns interessantes relatos na literatura, sendo estes: Impagliazzo (2005), Goldberg (2005), Schwarz et al. (2007), Martinho e Talamoni (2007).

\section{CONSIDERAÇÕES FINAIS}

A utilização de práticas pedagógicas alternativas na forma de expressões artísticas desenvolvidas em um minicurso para formação inicial de professores baseado na pedagogia de projetos se revelou frutífera. O resultado obtido das atividades desenvolvidas permite fortalecer o papel da metodologia de projetos como um dos meios importantes na formação de professores para a educação ambiental.

\section{AGRADECIMENTO}

CAPES, FAPEMIG e UFLA

\section{REFERÊNCIAS BIBLIOGRÁFICAS}

BRASIL, Ministério do Meio Ambiente. Carta da terra, 2000. Acesso em: 26 de maio de 2019. Disponível em: http://www.mma.gov.br/estruturas/agenda21/_arquivos/carta_terra.pdf.

BRASIL, Ministério do Meio Ambiente. Carta de Belgrado, 1975. Acesso em: 26 de maio de 2019. Disponível em: http://www.mma.gov.br/informma/item/8066-carta-de-belgrado. 
BRASIL, Nações Unidas. Carta final da Rio+20 "O FUTURO QUE QUEREMOS", 2012. Acesso em: 26 de maio de 2019. Disponível em: https://nacoesunidas.org/rio20-termina-e-documento-final-o-futuro-que-queremos-e-aprovadocom-elogios-e-reservas/.

BRASIL, Ministério do Meio Ambiente. Recomendações de Tbilisi, 1977. Acesso em: 26 de maio de 2019. Disponível em: http://www.mma.gov.br/educacao-ambiental/formacao/item/8065-recomenda\%C3\%A7\%C3\%B5es-detbilisi.html.

BRASIL, Ministério do Meio Ambiente. Declaração de Thessaloniki, 1997. Acesso em: 26 de maio de 2019. Disponível em: http://www.mma.gov.br/informma/item/8070-declara\%C3\%A7\%C3\%A3o-de-thessaloniki.html.

BRASIL, Ministério do Meio Ambiente. Tratado de Educação Ambiental para Sociedades Sustentáveis e Responsabilidade Global - ECO 92, 1992. Acesso em: 26 de maio de 2019. Disponível em: http://www.mma.gov.br/educacao-ambiental/formacao/item/8068-tratado-de-educa\%C3\%A7\%C3\%A3oambiental-para-sociedades-sustent\%C3\%A1veis-e-responsabilidade-global.html.

CARUSO, Francisco; SILVEIRA, Cristina. Quadrinhos para a cidadania. Imagens: História, Ciências, Saúde, Rio de Janeiro, v.16, n.1, jan.-mar. p.217-236, 2009.

COLOGNESE, Abilio Luiz; NASCIMENTO JÚNIOR, Antonio Fernandes. Produção e Apresentação de Material Didático e Pedagógico para o Ensino de Ciências e Biologia. In: CONGRESO INTERNACIONAL DE EDUCACIÓN SUPERIOR - IV TALLER INTERNACIONAL DE PEDAGOGIA DE LA EDUCACIÓN SUPERIOR, 4, 2004, La Habana - Cuba. Universidad 2004 - La Universidad por un Mundo Mejor. La Habana - Cuba: Ministerio de Educación Superior de la República de Cuba, 2004. p. 8890-8894.

FERREIRA, Marco Túlio Mendes; PAULA, Joberth Rainner Baliza de; SILVEIRA, Vicente Celentino; MINE, Patrícia Hitomi; NASCIMENTO JÚNIOR, Antonio Fernandes. Fantoches na praça: o relato de uma atividade do PIBID sobre o ensino das organelas celulares em espaços não formais. Revista da SBEnBIO, v. 5, p.1-10, 2012.

FERRY, Alexandre da Silva; NAGEM, Ronaldo Luiz. Analogia \& contra-analogia: um estudo sobre a viabilidade da comparação entre o modelo atômico de Bohr e o sistema solar por meio de um júri simulado. Experiências em Ensino de Ciências - V4(3), pp. 43-60, 2009.

FORMIGHIERI, Alice Pontes; BATISTTI, Cássia Monalisa Olívia; LEMOS, Juliana Mendes; KRINSKI, Kelly Cristina; SOUZA, Daniele Cristina de; NASCIMENTO JÚNIOR, Antonio Fernandes. Ecótone, Efeito De Borda E Ciclos Biogeoquímicos, Uma Forma Lúdica De Abordagem: Teatro Com Envolvimento De Fantoches Como Alternativa Para O Ensino. In: FÓRUM NACIONAL DO MEIO AMBIENTE - SUSTENTABILIDADE: COMPROMISSO COM A VIDA, 2006, SANTA ROSA, 4, 2006. Anais do IV Fórum nacional do meio ambiente - Sustentabilidade: compromisso com a vida. p. 138-148, 2006.

GALANTE, Mariana Ligabue; SOUZA, Daniele Cristina de; NASCIMENTO JÚNIOR, Antonio Fernandes. Produção de cartilha a partir de cartoons ecológicos como material de apoio pedagógico para o ensino em ecologia e educação ambiental. In: IV Fórum nacional do meio ambiente - Sustentabilidade: compromisso com a vida, 4, 2006, Santa Rosa. Anais do IV Fórum nacional do meio ambiente - Sustentabilidade: compromisso com a vida. p. 307-315, 2006.

GHELLERE, Polyana.; CASTRO, Fernanda Francielle de; JUSTINA Lourdes Aparecida Della. Painel da fotossíntese: um recurso didático para ensinar botânica. Anais da 2o ENCONTRO REGIONAL SUL DE ENSINO DE BIOLOGIA, 3ạ Jornada de Licenciatura em Ciências Biológicas da UFSC, Florianópolis, 02 a 04 de Novembro de 2006, p.1.

GOLDBERG, Luciane Germano; YUNES, Maria Angela Mattar; FREITAS, José Vicente de. O desenho infantil na ótica da ecologia do desenvolvimento humano. Psicologia em Estudo, Maringá, v. 10, n. 1, p. 97-106, jan./abr., 2005. 
GONÇALVES, Laise Vieira; CORTEZ, Marco Túlio Jorge; SANT ANA, Cecília. Ramos de Oliveira; NASCIMENTO JÚNIOR, Antonio Fernandes. Utilização do teatro de fantoches como prática de ensino: um relato de experiência do PIBID de biologia da Universidade Federal De Lavras, MG. Revista da SBEnBIO, v. 5, p. 1-10, 2012.

IMPAGLIAZZO, Marianina. A ciência do desenho e o desenho no ensino de ciência. Enseñanza de las Ciencias, Número Extra. VII Congreso, p.1-5, 2005.

LISBÔA, Lívia Lee; JUNQUEIRA, Heloisa; DEL PINO, José Cláudio. Histórias em quadrinhos como material didático alternativo para o trabalho de Educação Ambiental. Gaia Scientia, 2(1): 29 - 39, 2008.

MACAGNAN, Daiany Crystina; HEEP, Kátia Eloiza; FERLA, Graziela Cristina; FIORENTIN, Francieli; ELY, Daniela Fabiane; NASCIMENTO JÚNIOR, Antonio Fernandes. Produção de revistas ecológicas para o ensino e divulgação da ecologia e educação ambiental. In: CONGRESSO IBERO-AMERICANO DE EDUCAÇÃO AMBIENTAL, 5, 2006, Joinville. Anais do V Congresso Ibero-americano de Educação Ambiental, 2006. p. 1-3.

MACAGNAN, Daiany Crystina; NASCIMENTO JÚNIOR, Antonio Fernandes. O Teatro na Educação Ambiental “A Vida na Natureza Funciona Mais ou Menos Assim": Relato de Experiência. In: EPEA - ENCONTRO PARANAENSE DE EDUCAÇÃO AMBIENTAL. Anais do IX Encontro Paranaense de Educação Ambiental (EPEA). Guarapuava-PR, 2006.

MARTINHO, Luciana Rodrigues; TALAMONI, Jandira Liria Biscalquini. Representações sobre meio ambiente de alunos da quarta série do ensino fundamental. Ciência \& Educação, v. 13, n. 1, p. 1-13, 2007.

MELLO Maria Luiza Silveira; CORTELAZZO, Angelo Luiz. Uma proposta de dramatização como complemento didático para o estudo sobre cromatina e Cromossomos. Genética na Escola. n. 01.02, p.83-86, 2006.

MONTENEGRO Betânia; FREITAS, Ana Lúcia Ponte; MAGALHÃES, CALDAS, Pedro Jorge Caldas; SANTOS, Armênio Aguiar dos; VALE, Marcus Raimundo. O papel do teatro na divulgação científica: a experiência da seara da ciência. Ciência e Cultura. v. 57, n.4 São Paulo Oct./Dec. 2005.

NASCIMENTO JUNIOR, Antonio Fernandes; SOUZA, Daniele Cristina. O fazer artístico na popularização do conhecimento biológico: Relato de experiências. Rev. eletrônica Mestr. Educ. Ambient, v. 23, julho a dezembro de 2009.

NASCIMENTO JÚNIOR, Antonio Fernandes; COLOGNESE, Abílio Luiz; LUNKES, Juliana. Ester. ; TEIXEIRA, Vaniria Lysyk.; GOELZER, Luciana Peres. Cartoon Ecológico como Subsídio ao Ensino de Ecologia e Educação Ambiental para Alunos do Ensino Fundamental e Médio. In: I Seminário Internacional de Educação, 2001, Cianorte/PR. Anais do I Seminário Internacional de Educação. Cianorte, 2001. v. 1. p. 907-909.

OLIVEIRA, Cacilda Lages. Significado e contribuições da afetividade, no contexto da Metodologia de Projetos, na Educação Básica. Dissertação de mestrado CEFET-MG, Belo Horizonte, MG, 2006.

OLIVEIRA, Mário Cézar Amorim de. A origem dos seres vivos na biologia do ensino médio: construindo conhecimentos a partir da dinâmica do júri simulado. In: SIMPÓSIO LATINO AMERICANO E CARIBENHO DE EDUCAÇÃO EM CIÊNCIAS DO INTERNATIONAL COUNCIL OF ASSOCIATIONS FOR SCIENCE EDUCATION (ICASE), 4, 2011. Anais do V Encontro Regional Sul de Ensino de Biologia (EREBIO-SUL). 18 a 21 de setembro de 2011, p.1-11.

RAUBER, Khátia; NASCIMENTO JÚNIOR, Antonio Fernandes. Produção de uma revista pedagógica na área de Ecologia e Educação Ambiental. In: CONGRESSO IBERO-AMERICANO DE EDUCAÇÃO AMBIENTAL, 5, 2006, Joinville. Anais do V Congresso Ibero-americano de Educação Ambiental, p. 1-5.

REAL, Luciana Magalhães Corte; MENEZES, Crediné Silva de. Júri simulado: possibilidade de construção de conhecimento a partir de interações em um grupo. Marie Jane; NEVADO, Rosane. (Org.). Aprendizagem em rede na educação à distância. 1ed.Porto Alegre: Ricardo Lenz Editor, 2008, p. 93-102. v. 5, EAD. UFRGS pmd, 2008.

SANTOS Luiz Alfredo Mendes dos; NEIVERTH; Adelina; SOUZA, Daniele Cristina de; NASCIMENTO JÚNIOR, Antonio Fernandes. Teatro de fantoches: uma alternativa para a divulgação da Mata ciliar, ensino de ecologia e divulgação da fauna Paranaense. In: IX EPEA - Encontro Paranaense de Educação Ambiental. Guarapuava-PR, 1, 2, e 3 de setembro de 2006. Artigo registrado no evento sob no 76. ISBN 85-89346-27-7. 
SCHWARZ, Maria Luiza, SEVEGNANI, Lucia; ANDRÉ, Pierre. Representações da mata atlântica e de sua biodiversidade por meio dos desenhos infantis. Ciência \& Educação, v. 13, n. 3, p. 369-388, 2007.

SILVEIRA, Alessandro Frederico da; ATAÍDE, Ana Raquel Pereira de; FREIRE, Morgana Ligia de Farias. Atividades lúdicas no ensino de ciências: Uma adaptação metodológica através do teatro para comunicar a ciência a todos. Educar em Revista (Impresso), Curitiba, n. 34, p. 251-262, 2009.

SOUZA, Daniele Cristina de; OLIVEIRA, Maria Aparecida de; NEIVERTH, Adeline; NASCIMENTO JÚNIOR, Antonio Fernandes. Produção de painéis montáveis de imã como recurso para o ensino de ecologia a partir do comportamento da capivara (Hidrochoerus hidrochoreis. Fórum Ambiental da Alta Paulista, v. III, p. 813-823, 2008. 